\title{
European Association of Faculties of Pharmacy (EAFP) Virtual Conference Proceedings 2020
}

\author{
Synergism in Pharmacy Education: A New Dimension \\ Hosted by the Department of Pharmacy, University of Malta
}

\author{
Experiential learning in a gamified simulation \\ detected by semantic analysis \\ D. L. $\operatorname{Hope}^{1}(\mathbb{D})$, G. D. $\operatorname{Rogers}^{2}$ (D) G. D. Grant
M. A.
Ming \\ ${ }^{1}$ School of Pharmacy and Pharmacology and Quality Use of \\ Medicines Network, Griffith University, Gold Coast, Australia

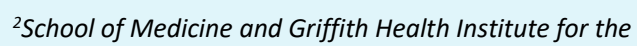 \\ Development of Education and Scholarship (Health IDEAS), Griffith \\ University, Gold Coast, Australia \\ ${ }^{3}$ School of Pharmacy and Pharmacology and Quality Use of \\ Medicines Network, Griffith University, Gold Coast, Australia \\ ${ }^{4}$ School of Pharmacy and Pharmacology and Quality Use of \\ Medicines Network, Griffith University, Gold Coast, Australia
}

Introduction: An extended gamified simulation was developed as a capstone activity for a new Bachelor of Pharmacy (B.Pharm.) programme. The simulation aimed to provide an authentic learning experience in which students competitively ran face-to-face pharmacies, acting as autonomous pharmacists, to develop their professional and collaborative skills. The game delivered constant assessments scaffolded over time. Students conducted daily team debriefing meetings and wrote multiple individual reflective journals during the three-week simulation. The research aimed to evaluate students' experience of such an intensive and emotionally impactful learning activity.

Materials and methods: All participants submitted textbased reflective journals (200 to 500 words) in the gamified simulation. Content and thematic analysis were conducted on journal text using the Leximancer system, which allows for large volumes of text to be independently analysed, using semantic frequency and co-occurrence to automatically detect concepts and cluster them into themes (Smith and Humphreys, 2006).

Results: From 2016 to 2018, 733 reflective journals were submitted by simulation participants, including 94 full-time B.Pharm. students and 29 part-time Master of Pharmacy students. Semantic analysis of the journal text revealed four primary themes: teamwork, medicines provision, patientcentredness, and future practice. Leximancer heat mapping identified teamwork as the most important theme, with component concepts related to daily collaborations. Medicines provision identified students' focus on casework, including dispensing and counselling, whereas patientcentredness was about providing care and information to the patient. Future practice as a theme identified students' translation of the experiential learning to their future practice and development of real-life skills.

Conclusions: Students' experience in a gamified simulation revealed that such an activity could aid in collaboration, team learning, help participants develop their patient-centredness and translate to future professional practice.

\section{Reference}

Smith, A. E., \& Humphreys, M. S. (2006). Evaluation of unsupervised semantic mapping of natural language with Leximancer concept mapping. Behavior research methods, 38(2), 262-279. https://doi.org/10.3758/bf03192778 


\section{Introduction of a communication skills training programme for pre-registration pharmacists in a tertiary hospital in Singapore}

C. Loh, P. Tan, A. Ng

KK Women's \& Children's Hospital, Singapore

Introduction: Effective communication of pharmacists with patients and other healthcare co-workers is vital in improving patient safety, clinical outcomes, and overall satisfaction. A communication skills training programme was introduced into the existing pre-registration pharmacist training framework at KK Hospital Outpatient Pharmacy, aiming to improve the communication skills of pre-registration pharmacists.

Materials and methods: At the beginning of attachment, preregistration pharmacists participate in: Self-reading of Patient-centred Communication Tools (PaCT) (Grice et al., 2017) and slides on communication, as well as reflection of authentic communication challenges. Midway through attachment, there is a discussion whereby each preregistration pharmacist shares their communication challenge. Pharmacist-led discussion facilitates their understanding of $\mathrm{PaCT}$ relevant to their communication challenges. They also engage in role-plays that portray common communication issues to further explore how to apply PaCT. After that, pre-registration pharmacists are given self-assessment to help them identify areas for improvement. Their interactions with actual patients and other co-workers are assessed by pharmacists using modified PaCT ( $\mathrm{mPaCT}$ ).

Results: Two cohorts of six students each participated in this pilot training from May to December 2018. As a learning tool, $75 \%$ of pre-registration pharmacists found role-play and facilitated discussions more effective than self-reading. Selfassessment showed that pre-registration pharmacists recognised how to apply PaCTs. They were able to utilise the communication tools learnt during their dispensing and interaction with co-workers.

Conclusions: Pre-registration pharmacists' communication skills showed improvement with the programme. The identified communication challenges were incorporated into self-learning slides for future cohorts. The programme is currently being modified for pharmacy technicians.

\section{Reference}

Grice, G. R., Gattas, N. M., Prosser, T., Voorhees, M., Kebodeaux, C., Tiemeier, A., Berry, T. M., Wilson, A. G., Mann, J., \& Juang, P. (2017). Design and Validation of Patient-Centered Communication Tools (PaCT) to Measure Students' Communication Skills. American journal of pharmaceutical education, 81(8), 5927. https://doi.org/10.5688/ajpe5927

\section{Pharmacy students' attitude towards academic dishonesty}

J. Dauksiene, V. Raudyte, S. Rimkute

Lithuanian University of Health Sciences, Drug Technology and Social Pharmacy Department, Kaunas, Lithuania

Introduction: Academic honesty is an ethical principle based on openness, confidence, respect, integrity, and responsibility, applicable to academic activities. Academic dishonesty is a relevant problem pervading all areas of science and education. A high number of studies showed a direct relationship between the way students behave at education institutions and how often they tend to be ethical and honest in their work environment. The main aim of the study was to explore the attitude of pharmacy students towards academic dishonesty.

Materials and methods: Qualitative and quantitative methods were combined. First stage: interviews with 13 fifthyear pharmacy students helped identify the reasons for cheating, attitude towards cheating colleagues, and expectations of academic regulations. Second stage: The questionnaire was created based on qualitative research and distributed among first to third-year pharmacy students.

Results: Academic dishonesty is widespread among pharmacy students (97.8\%). Students are distributed into two main categories: those with a long cheating experience (since high school, 85.1\%) and those who started cheating recently at the university (14.9\%). The most common way of cheating is through using additional means (notes, drawers, mobile phones, smart bracelets, etc.) during lectures and exams (67\%). Another prevalent way of cheating is to copy other students' work (75.8\%). The most uncommon means of cheating is buying various tasks for money (3.3\%). Regardless of the average and the course, the main factors for cheating are good grades $(62.7 \%)$ and excessive workload (76.9\%). The most effective preventive measure of academic dishonesty is teachers' attention to all educational activities (32\%). Students' expulsion from university is too strict and ineffective as a preventive measure (3\%).

Conclusions: Academic dishonesty is a very relevant problem among students, manifested in various ways of cheating due to different incentives. It is necessary to take new preventive measures to avoid this problem and encourage students to be honest academically. 


\section{Implementation of the practical teaching of parenteral nutrition and cytotoxic drugs compounding to the pharmaceutical technology course}

W. Brniak ${ }^{1,2}$, J. Szlęk ${ }^{1}$, R. Jachowicz ${ }^{1}$

${ }^{1}$ Chair of Pharmaceutical Technology and Biopharmaceutics, Faculty of Pharmacy, Jagiellonian University Medical College, Krakow, Poland

${ }^{2}$ Hospital Pharmacy, Stanley Dudrick's Memorial Hospital, Skawina, Poland

Introduction: The mission of the Jagiellonian University Faculty of Pharmacy is to train qualified personnel, experts in the field of pharmacy. The faculty offers students about 100 courses, half of which are obligatory and cover specific learning outcomes described in the National Education Standards Preparing for the Profession of Pharmacist. Four pharmaceutical technology courses include 320 teaching hours, among which 70 hours are devoted to sterile preparations compounding. The programme of this course has changed. The level of education was raised so that students acquire experience and competence in preparing sterile medications not commercially available for patients.

Materials and methods: The cooperation with both hospital pharmacies and industry was strengthened to achieve the outcomes established in the National Standards. The teaching staff participated in a series of professional training for pharmacists. An automatic compounder for the preparation of parenteral nutrition admixtures and a scale with the appropriate software for cytotoxic drugs compounding have become available in the university's clean room area for students teaching. Installed equipment was the same as used in hospital pharmacies; therefore, it enabled simulation of the actual environment in practical training. Moreover, experienced hospital pharmacists were involved in the practical training.

Results: The opportunity to prepare parenteral nutrition admixtures and cytotoxic drugs in simulated real-like conditions allows students to develop practical skills and competencies to meet the National Standards. Moreover, it serves as an undergraduate basic training before the sixmonth internship. The overall satisfaction of students from the course, and their motivation to study, were considerably improved after the changes.

Conclusions: Implementation of the practical teaching of parenteral compounding into the pharmaceutical technology course improved the quality of education and increased the ability to develop practical skills needed for future practice and work in hospital pharmacy.

\section{Educational needs assessment to design a training for Greek pharmacists to deliver a public health service}

\author{
A. Peletidi1-3, R. Kayyali
}

${ }^{1}$ Pharmacy Programme, Department of Life and Health Sciences, School of Life Sciences and Engineering, University of Nicosia, Nicosia, Cyprus

${ }^{2}$ Department of Pharmacy, School of Life Sciences, Pharmacy and Chemistry, Kingston University, London, United Kingdom

${ }^{3}$ Department of Pharmacy, Faculty of Health Sciences, Aristotle University of Thessaloniki, Thessaloniki, Greece

Introduction: Pharmacists are in a great position to help individuals make a behavioural change. Communication is a fundamental skill of pharmacists, as it benefits the pharmacist-client/patient relationship. The patient-centred approach is recommended for effective communication. Greek pharmacists tend to use a paternalistic approach in their consultations (Peletidi, Nabhani-Gebara \& Kayyali, 2019), which does not favour the patient-centred approach. This study aimed to identify the current knowledge and educational needs of Greek pharmacists regarding obesity and running a weight-management service.

Materials and methods: All pharmacists in Patras were informed about the study through the Pharmaceutical Association of Achaia (PAA). Semi-structured face-to-face interviews were conducted, each lasting for roughly 15 minutes. The interview schedule included seven open-ended questions as well as demographic information. Upon data collection, interviews were transcribed verbatim and then anonymised. They were analysed using a mixed analytical method, including thematic and content analysis. The study was ethically approved by the Kingston University's Ethics Committee and the PAA.

Results: Twenty-six pharmacists, mainly males $(61.5 \%, n=16)$ participated. Pharmacists explained that their current knowledge is based both on their university studies and their working experience, and they think that it is not enough as they stated that their knowledge level on obesity and weightmanagement is minimal to moderate $(n=19)$ without any specialised knowledge on the topic. Most pharmacists $(n=11)$ suggested that the training format should be in the form of lectures followed by group discussions. On the issue of how many sessions they felt were needed, 16 participants estimated that one to two sessions would be adequate. Interestingly, 15 participants stated that there was no need for refresher training.

Conclusions: To our knowledge, this was the first and only study that identified Greek pharmacists' educational needs and training preferences to design a training model allowing them to expand their clinical role in offering pharmacy-led public health services. 


\section{Reference}

Peletidi, A., Nabhani-Gebara, S., \& Kayyali, R. (2019). The Role of Pharmacists in Cardiovascular Disease Prevention: Qualitative Studies from the United Kingdom and Greece. Journal of research in pharmacy practice, 8(3), 112-122. https://doi.org/10.4103/jrpp.JRPP_19_3

\section{Experience of health technology assessment implementation in the educational system in Ukraine}

O. Pokotylo

I. Horbachevsky Ternopil National Medical University, Ternopil, Ukraine

Introduction: The Ministry of Health of Ukraine is currently actively implementing the Health Technology Assessment (HTA) as the positive experience of European countries to determine priorities in the Ukrainian healthcare system. HTA is a scientific approach for determining the list of medicines and medical services that are expedient to finance and procured by the state at the expense of taxpayers. The need for highly qualified health technology experts to effectively implement the National programme is a topical issue in the Ukrainian universities' educational process. Therefore, the assessment of current potential of educational programmes for this need was the purpose of the study.

Materials and methods: This study used the method of analysing the current state of HTA training in Ukraine, comparing it with other world-leading countries, and forecasting further perspectives in this field.

Results: HTA is a multidisciplinary process that summarises information about medical, social, economic, and ethical issues related to the use of health technology in a systematic, transparent, unbiased, robust manner. Accordingly, the target audience who needs the HTA training programme was determined: Ministry of Health experts, members of tendering committees of medical institutions or formulary commissions, medical practitioners, pharmacists, patient organisations, and medical and pharmacy graduates. Nowadays, professional and powerful Ukrainian HTA training resources exist based on national universities, such as the Private HTA Academy. Priorities in the training programme were the modern methodology of organising and conducting HTA, scientific research (evidence-based medicine), and decision-making processes.

Conclusions: Effective implementation of progressive innovation HTA requires the involvement of highly qualified specialists, which is a promising area of healthcare development.

\section{Enhancing student understanding of grading criteria}

E. Lundkvist

Uppsala University, Uppsala, Sweden

Introduction: Written grading criteria for student learning and exam assessment are used in advanced pharmacotherapy courses. Rust and authors (2003) showed that students who undertook a pre-assessment workshop, marking and discussing an exemplar assignment, performed significantly better than those who did not participate (Rust, Price \& O'Donovan, 2003). Inspired by this research, it was decided to implement a similar approach to enhance student understanding of the criteria and stimulate learning.

Materials and methods: In 2016, an optional workshop was implemented a few days before the written exam. Working in small groups of three to four, students first looked at a written exam from a previous term and then assessed an anonymised answer using the grading criteria. The workshop ended with a whole class discussion about grading. Regular course evaluation was used to get the feedback of students.

Results: The results showed that $69 \%$ of workshop participants passed the written exam on the first attempt compared to $46 \%$ for non-participants. Differences may be influenced by selection bias, i.e. those more likely to attend the workshop might also be more likely to perform well on the exam. Based on course evaluations, students appreciate the workshop. The average score was 5.2 on a six-level scale, with comments like "gave a good insight into assessment and grading" and "gave a deeper understanding of how answers can differ, why you get the different grades, and how teachers reason when assessing."

Conclusion: Our findings indicate that this approach may be an adequate means to help students understand the grading criteria, thereby enabling them to reach the learning outcomes and pass the exam, but the impact of the potential selection bias must be further explored.

\section{Reference}

Rust, C., Price, M., \& O'Donovan, B. (2003). Improving Students' Learning by Developing their Understanding of Assessment Criteria and Processes. Assessment \& Evaluation in Higher Education, 28(2), 147-164. https://doi.org/10.1080/02602930301671 


\section{Critique of a published study during advanced experiential placements}

R. Agius (D), D. Sammut Alessi (D), A. Cutajar (D), L. Grech (D), L. M. Azzopardi (D)

Department of Pharmacy, Faculty of Medicine and Surgery, University of Malta, Msida, Malta

Introduction: The postgraduate Doctor of Pharmacy degree, run by the University of Malta in collaboration with the University of Illinois, Chicago, enables students to carry out a six-week advanced experiential placement. Doctorate students can opt for a Medicines Information placement during this time. Providing drug information is an essential responsibility of pharmacists, and they need to be skilful in information retrieval, interpretation, and clinical application. One of the aims of the placement is for the development of critical appraisal skills of literature.

Materials and methods: The preceptors choose a published study related to a subject encountered in clinical practice. The article is selected from a peer-reviewed journal based on its clinical relevance or educational value. The study is assigned to doctorate students during their experiential placement, and the preceptor explains the task purposes. Students are expected to apply critical literature evaluation skills simulating real-life situations and are assessed for reporting, analysing, and appraising scientific research.

Results: Presenting the article using slides helped to convey the data under discussion. During the presentation, students delivered the fundamentals of the published study focusing on the hypothesis, study design (including study type, population, randomisation, inclusion, and exclusion criteria), methodology with outcome measures, results, interpretation (including limitations, strengths, and weaknesses), and clinical context. This activity evaluated students' understanding and ability to critique published clinical studies and enabled an academic discussion with preceptors and other pharmacists.

Conclusions: In an era of considerable information flow, it is challenging to assess the validity, reliability, and relevance of information. This educational activity enabled students to improve knowledge and critical appraisal skills to analyse presented data and keep up-to-date with published literature.

\section{Enquiry-based learning in advanced pharmacy practice experiential rotations}

\author{
D. Sammut Alessi (D), R. Agius (D), A. Cutajar (D), L. Grech (D) \\ L. M. Azzopardi iD
}

Department of Pharmacy, Faculty of Medicine and Surgery, University of Malta, Msida, Malta

Introduction: During the Advanced Pharmacy Practice Experiential offered by the University of Malta for the postgraduate Doctorate of Pharmacy programme, students are challenged with enquiry-based learning during a hospitalbased Medicines Information rotation. This approach enables the engagement of students with a complex clinical scenario by using the enquiry process.

Material and methods: The preceptor develops a training plan at the beginning of the rotation based on the students' self-reported strengths, interests, and areas for improvement. During the rotation, students are presented with a range of real-life medicines information enquiries. Topics delved into include: parenteral drug administration, toxicology, therapeutic drug monitoring, palliative care, travel medicine and prescribing in special populations, such as paediatrics, liver disease, and renal impairment. Different degrees of enquiry complexity are presented for discussion, starting from basic data retrieval up to data interpretation, analysis, and expressing a professional opinion following the six levels in Bloom's Taxonomy.

Results: Students exercise their verbal and written communication skills through phone scenarios, presentations in front of an audience, and the documentation of queries. They engage in a minimum of ten medicines information cases per six-week rotation. Two of these cases are shaped in a structured, reflective format for students to draw on the literature, and one case is presented as a case-based discussion. Preceptors highlight best the practice in information delivery through regular assessment and feedback, fostering the engagement of students to explore different avenues of information and experience collaborative work.

Conclusions: Enquiry-based learning has multiple benefits and promotes critical thinking and self-directed learning (Cuéllar \& Ginsburg, 2016). This training opportunity enables students to participate in advanced pharmacy practice activities by incorporating research into the medication use process.

\section{Reference}

Cuéllar \& Ginsburg, 2016. Preceptor's handbook for pharmacists, Third edition. ASHP Publications, Bethesda, Maryland 


\section{Entrustable professional activities (EPAS) for distance-based global Doctor of Pharmacy (Pharm.D.) and Master of Science (MS) students}

\author{
S.E. Gleason, P.M. Reynolds, M.E. Thompson, R.J. Altiere
}

University of Colorado Skaggs School of Pharmacy and

Pharmaceutical Sciences, Aurora, Colorado, United States

Introduction: Core EPAs for New Pharmacy Graduates were developed by the American Association of Colleges of Pharmacy (AACP) to promote practice-ready graduates. The University of Colorado Skaggs School of Pharmacy recently introduced EPAs for entry-level students (2017) and midcareer, distance-education, post-baccalaureate Pharm.D., and MS students (2019) curricular pathways/programmes. The results of EPA evaluations by distance students are reported.

Materials and methods: Available EPAs included AACP Core EPAs, designed for entry-level Advanced Pharmacy Practice Experience (APPE) readiness, and more robust, facultydriven, school-specific EPAs for mid-career Pharm.D. and MS students with greater skill levels and local practice needs. Students may complete EPAs at Introductory Pharmacy Practice Experience (IPPE) sites, work settings, and APPE sites. Students must complete 20 EPAs, with a minimum number of six practice domains in each. For each EPA, students and preceptors rate level of entrustment. To pass, both must rate entrustment at a level three (action with reactive supervision) of five levels (1=observation only, 5 =teaches others). Students must choose ten EPAs for further refinement. Data are tracked through the school's learning management system (eValue).

Results: Summer and autumn 2019 terms reveal 31 EPAs completed by five students (four countries). Three are refined skills; 16 have been preceptor-assessed. Mean entrustment scores were as follows: all=3.90 ( $n=31)$, graded by students=3.75 $(n=16)$, and graded by preceptors $=3.40 \quad(n=16)$. Score comparison: preceptor<student $=18.75 \%$, preceptor $>$ student $=6.25 \%$, preceptor same as student $=75.00 \% ; 15 / 16$ EPAs approved. Number of EPAs by Domain: Patient care provider $=13$, Interprofessional team member $=1$, Population health promoter=2, Information master $=4$, Practice manager $=2$, Self-developer $=0$.

Conclusions: Faculty-driven, school-specific EPAs, allow global, mid-career pharmacists to practice wide-ranging skills that meet passing entrustment levels. EPA choice allows midcareer global students to meet professional development and local practice needs while aligning with several of the International Pharmaceutical Federation's Nanjing Statements and Workforce Development Goals. Consideration of local needs and opportunities should occur when offering EPAs.

\section{The use of international non-proprietary names (INN) to facilitate learning pharmacology}

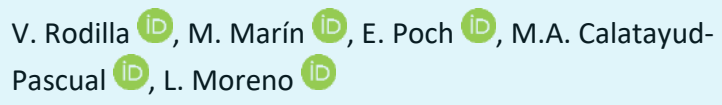

Department of Pharmacy, Faculty of Health Sciences, Universidad CEU-Cardenal Herrera, Valencia, Spain

Introduction: INN are widely used in pharmacology teaching to help students recognise the mechanism of action of drugs or the therapeutic group to which they belong. However, many students are not aware of the INN nomenclature system (World Health Organization, 2017). This work aimed to explain the INN nomenclature system to students to help them better understand the meaning of drug names, substituting rote learning with meaningful learning.

Material and methods: Four groups of students were selected. The first two groups consisted of second-year dentistry students enrolled in Pharmacology courses, and the other two groups included pharmacy students (year four and year five) enrolled in Pharmacology and Clinical Pharmacy or Pharmaceutical biotechnology, respectively. Year 5 pharmacy students and one of the dentistry groups were given at least one formal lecture on INN nomenclature and INN stems at the beginning of the academic year (trained), while the other two groups did not receive it (untrained). At the end of the term, all students were asked to fill a short anonymous questionnaire, and $240 \mathrm{did}$.

Results: More untrained students reported having difficulty learning and retaining drug names (89\% untrained vs. $55 \%$ trained; $\chi^{2}$ test, $p<0.001$ ). Receiving INN training helps students recognise the pharmacological properties of some drugs (73\% trained vs. $47 \%$ untrained; $\chi^{2}$ test, $p<0.001$ ). Similar percentages of students realised that INN stems helped them to better study and understand pharmacology ( $85 \%$ trained vs. $79 \%$ untrained; $\chi^{2}$ test, $p=0.28$ ).

Conclusions: Understanding the INN nomenclature system helped students learn and retain drug names. It also allowed them to recognise the pharmaceutical properties of certain drugs and study pharmacology in a more meaningful and solid manner.

\section{Reference}

World Health Organization. (2017). Naming of medicines: survey about International Nonproprietary Names (INN). WHO Drug Information, 31(4), 581585. WHO. Available at: https://apps.who.int/iris/handle/10665/330945 


\section{Assessment of competencies acquired by pharmacy students using objective structured clinical examination (OSCE) \\ C. Balaguer-Fernández (D), M.A. Calatayud-Pascual (D), L. Moreno ${ }^{D}$, A. López-Castellano $D$, V. Rodilla \\ Department of Pharmacy, Faculty of Health Sciences, Universidad CEU-Cardenal Herrera, Valencia, Spain}

Introduction: Acquisition of competencies in pharmacy education is of great importance to training good pharmaceutical practitioners. Because of its reliability and validity, OSCE has become the standard for the evaluation of clinical skills among pharmacy students in many countries (Shirwaikar, 2015). This study describes the application of OSCE for assessing several key competencies among pharmacy students in the last two academic years (2017-19).

Material and methods: A five-station validated OSCE was implemented. The competencies tested in these OSCE included inter alia student knowledge, patient counselling and communication (communication skills), and acquisition and implementation of technical/clinical skills.

Results: During the two academic years assessed (2017-19), 72 students were evaluated using five OSCE stations/year. Altogether $13.5 \%$ of competencies assessed were communication skills, 35\% corresponded to technical/clinical skills, and the remaining $51.5 \%$ evaluated knowledge acquisition. A survey among participating students showed a high level of satisfaction (4.95/6). Students felt OSCE was adequately structured and assessed the clinical/communication skills needed for a professional pharmacist.

Conclusions: OSCE is an essential tool for the assessment of clinical competencies and complements traditional examinations. Furthermore, it allows verification of clinical and technical abilities as well as communication skills among future pharmacists, which otherwise are extremely difficult to assess (Harden \& Gleeson, 1979).

\section{References}

Shirwaikar A. (2015). Objective structured clinical examination (OSCE) in pharmacy education - a trend. Pharmacy practice, 13(4), 627. https://doi.org/10.18549/PharmPract.2015.04.627

Harden, R. M., \& Gleeson, F. A. (1979). Assessment of clinical competence using an objective structured clinical examination (OSCE). Medical education, 13(1), 41-54

\section{Utilising multiple active learning strategies to maximise student engagement}

N.Ward

Leicester School of Pharmacy, De Montfort University, Leicester, United Kingdom

Introduction: It has been recognised since the 1600 s that students tend to learn more if teachers spend less time teaching and the students spent less time passively listening (UK Centre for Materials Education, 2012). Pharmacy students have sometimes found nutrition a challenging topic to engage with as they do not always perceive the relevance to future practice or the significance of social influences on health behaviours. In delivering teaching on this topic, a range of different active learning strategies was introduced in 2018/19 to increase student engagement and provide diverse opportunities for learning within and outside the classroom.

Materials and methods: Several strategies were utilised to increase student understanding of both scientific and social aspects of nutrition through independent learning, interactive large-group teaching, workshops, and seminars. These included reviewing online news articles, watching screencasts with embedded quizzes, and online polling. All students attended a workshop that consisted of eight workstations involving different relevant activities. A second large-group teaching session helped consolidate their learning, including a debate on controversial issues relating to obesity. Integration with the scientific elements of the curriculum was achieved through co-delivered case studybased workshops. Student feedback on the sessions was collated and evaluated.

Results: All students positively evaluated the workshop, with the two most popular workstations being Oral Nutritional Supplements (trying supplements gave them "an insight into the patient's perspective") and nasogastric (NG) feeding (observing a drug-feed interaction "made me think about the thought that must go into safely administering medicines through the NG tube").

Conclusions: Overall, student engagement and feedback were positive, with students being able to actively contribute to discussions and debates on both scientific and social factors relating to nutrition. The use of these strategies is ongoing.

\section{Reference}

UK Centre for Materials Education. (2012). Active Learning. Higher Education Academy. Available at:

https://www.heacademy.ac.uk/system/files/active-learning.pdf 


\section{Interactive rooftop garden for learning medicinal plants}

S. Sibul, M. Pelska, K. Eha

Tallinn Health Care College, Tallinn, Estonia

Introduction: Studies have revealed that knowledge of plants, especially medicinal plants, has decreased over the years. It was necessary to create an accessible herb garden on the rooftop of Tallinn Health Care College with labelled plants to simplify the learning process. This study aimed to design a novel educational and interactive tool for the rooftop garden of Tallinn Health Care College to increase awareness about medicinal plants and their effect on the human body.

Materials and methods: This research is based on scientific data of 60 plants entered into the Plantsmap database. Each plant entry is linked to a QR code. The following plant data were added: Latin and Estonian plant names, synonyms, taxonomic units, botanical information, and information on the plant active ingredients and usage. All plants were labelled with common and scientific names and also QRcodes.

Results: Rooftop Garden at Tallinn Health Care College is a popular place for students to relax. The interactive learning environment encourages students to learn about plants individually and at suitable times. The database is reviewed by a specialist and updated regularly by adding new information and pictures of plants. The learning tool is accessible to all visitors with a mobile application for scanning QR-codes.

Conclusions: The existence of a rooftop garden in the college allows students to explore the plants independently. QR-code plant labels facilitate access to evidence-based information. As a result, students become more aware of the plants and their use; the learning process is flexible and interactive.
Partnering in pharmacy education: The success of Slovak pharmacy students in compounding pharmaceutical preparations

V. Šimunková, J. Valentová, M. Hrčka Dubničková (D, J. Tóth (D), P. Mučaji, M. Molitorisová $D$

Comenius University in Bratislava, Faculty of Pharmacy, Slovakia

Introduction: With inter-connectivity and competitiveness developing rapidly, new opportunities are emerging for the educational system. Compounding individual drug formulations represents an inherent component of the pharmaceutical technology curriculum at the Faculty of Pharmacy, Comenius University in Bratislava ("FPharm CU"). Increasing demand for personalised pharmaceutical products has led to a revival in pharmaceutical compounding. The present case study aims to demonstrate an innovative approach in education processes via a synergy between academy and practice.

Material and methods: The study involved 60 fourth-year students of the Master of Pharmacy programme, two academic staff members of FPharm $\mathrm{CU}$, and an external partner, namely Fagron, a.s., CZ (belonging to the Dutch pharmaceutical compounding company Fagron B.V.). The educational tool was based on direct communication between them. Firstly, the company was invited to participate in educational activities, specifically lectures and hands-on training. The students were required to engage in drug formulation compounding, to meet quality standards and other required characteristics. Secondly, eleven students participated in a local compounding competition, followed by an international competition organised between the four existing Faculties of Pharmacy of the Czech and Slovak Republics. The FPharm CU was represented by three students who won the international round. Performance criteria included theoretical knowledge, practical skills, and students' personal approach.

Results: The study resulted in the penetration of theory into practice, with the principal outcomes being high performance, motivation, and innovations in compounding. In addition, the students from the FPharm CU in Bratislava won the international competition.

Conclusions: This case study highlighted the potential usefulness of public-private partnerships. It led to the identification of talents and innovations in teaching. It also improved motivation and performance and is likely to offer win-win solutions for all stakeholders. 


\section{Introducing the risk concept in pharmaceutical studies: From art to science}

\author{
M. Attard Pizzuto (D), L.M. Azzopardi ${ }^{(D)}$, A. Serracino-Inglott
}

Department of Pharmacy, Faculty of Medicine and Surgery,

University of Malta, Msida, Malta

Introduction: Risk management is an evolving aspect in different pharmaceutical scenarios. Risk represents stages in science where imagination plays a significant part. The science of risk in pharmaceutical processes was, until recently, mainly unmarked and unexamined as a scientific process. Students following courses at the Department of Pharmacy within the University of Malta undertook different projects related to risk in pharmaceutical processes to reflect through practice fieldwork on the concept of risk.

Materials and methods: Students following the Bachelor of Science in Pharmaceutical Technology (BSc Pharm Tech) and Master of Science in Pharmacy (MSc Pharmacy) programmes carried out a project on an aspect related to risk and risk management. Different research methods were used to gather scientific knowledge on the concept of risk.

Results: Research on the area of risk was undertaken by seven students from 2017 onwards, with three students following the MSc Pharmacy degree and four following the BSc Pharm Tech degree. Pharmaceutical technology students contributed to research in areas related to the risk in the pharmaceutical industry, risks in pharmaceutical processes, perception of risk among pharmaceutical stakeholders, and the risk of using returned medicines. Master students contributed to research in areas related to the risk of data integrity of electronic records in the pharmaceutical industry, risk assessments in pharmaceutical processes, and risk management in the manufacture of solid oral dosage forms. Students adopted different data collection methods, including questionnaires, interviews, and focus groups.

Conclusions: Through this teaching model, students participated in research projects undertaken in collaboration with stakeholders, including the pharmaceutical industry, health professionals, and patients. This situation provided the opportunity for students to understand the implications of the science of risk in pharmaceutical processes and reflect on the perspectives of the society of risk identification and mitigation strategies.

\section{Development of an applied course in biochemistry for pharmacy students}

\author{
J. Vella Szijj, M. Attard Pizzuto (D) F. Wirth D, S. Falzon, \\ L. Mifsud Buhagiar, M. Gauci, L. Grech (D), \\ A. Serracino-Inglott (D) L.M. Azzopardi (D) \\ Department of Pharmacy, Faculty of Medicine and Surgery, University \\ of Malta, Msida, Malta
}

Introduction: Students reading for a Bachelor of Science in Pharmaceutical Sciences at the Department of Pharmacy at the University of Malta follow a compulsory study unit in biochemistry. The study unit consists of four ECTS and is delivered via lectures during the second year of studies. The aim of the academic review was to update the biochemistry study unit to reflect an approach to integrate the basic scientific concepts with the application to patient conditions and pharmaceutical aspects.

Materials and methods: The principal topics to be covered in the study unit were identified, and the material for the lectures was developed by clinical academic staff who could relate the scientific aspects to relevant aspects in pharmacy.

Results: Topics included were: 1) Transmission of information focusing on neurotransmitters and pharmacogenetics (eight hours), 2) Metabolic pathways including endocrine control, lipid metabolism, carbohydrates (eight hours), and 3) Physiological processes covering inflammatory reactions, cancer, cardiac signalling, fluid and electrolyte balance and aspects of toxicology (ten hours). The topics were delivered through lectures with clinical examples so as to support students to grasp the fundamentals and apply them within pharmaceutical contexts. The sessions were delivered by nine members of staff, each focusing on their area of clinical experience.

Conclusions: The revised study unit presents the scientific foundations merged with the implications for practice and is an attempt to help students break the silos in the teaching model. Assimilating basic scientific principles within clinical sciences provides an example of how students will be putting their competences to use in their pharmaceutical career. 


\section{Development of competences and skills during pharmaceutics practical sessions}

\author{
N. Sammut Bartolo ${ }^{D}$, LM. Azzopardi ${ }^{(D)}$
}

Department of Pharmacy, University of Malta, Msida, Malta

Introduction: The activities undergraduate students are exposed to should equip them with transferrable skills which can be applied during their daily working routine. The pharmaceutics practical sessions, which form part of the Bachelor of Science (Honours) in Pharmaceutical Science, are a good opportunity to ingrain good practices in students.

Materials and methods: A handbook was developed for pharmaceutics practical sessions. The introduction part of the handbook outlines good laboratory practices, including the use of appropriate safety gear, Standard Operating Procedures (SOPS), Material Safety Data Sheets (MSDS), presenting results and good documentation practices. Students are presented with the instructions to follow during the respective practical and the scheme used for marking.

Results: Students follow two practical sessions in the first and second year of the undergraduate programme and three sessions during their third year. Each session is three hours long. Before attending practical sessions, students are required to read the SOPs and MSDS, which are highlighted in the respective practical description. SOPs and MSDS are made available to students online and in printed format in the laboratory. At the end of each practical, students have to clean the work area and glassware and separate any waste generated according to the type of waste. Criteria used to assess students include whether the student was wearing the required safety garments, participation in practical work session, documentation practices, and the calculations and inferences reached by the student.

Conclusions: The developed practicals focus on developing competences in following quality systems, laboratory procedures, documentation and report writing.

\section{Novel coronavirus (2019-nCoV) seminar for healthcare professionals: An interdisciplinary academic initiative}

A. Serracino Inglott 1,2 (D) C. Gauci ${ }^{3,4}$, C. Muscat ${ }^{1,2}$,

S. Falzon ${ }^{1,2}$, C. Camilleri ${ }^{1,2}$, K. Vella ${ }^{1,2}$, A. Attard ${ }^{1,2}$,

L. Mifsud Buhagiar ${ }^{1,2}$

${ }^{1}$ Department of Pharmacy, Faculty of Medicine and Surgery, University of Malta, Msida, Malta

${ }^{2}$ Malta Medicines Authority, Malta Life Sciences Park, San Ġwann, Malta

${ }^{3}$ Superintendence of Public Health, Department for Health Regulation, Pieta', Malta

${ }^{4}$ Public Health Department, Faculty of Medicine and Surgery, University of Malta, Msida, Malta

Introduction: The Academy for Patient-Centred Excellence and Innovation in Regulatory Sciences, under the auspices of the Malta Medicines Authority (MMA), serves as a central platform to disseminate aspects of research and innovation and engage healthcare professionals in the work of Medicines Intelligence and Access Unit and Advanced Scientific Initiatives Directorate within the regulatory authority. The novel coronavirus (2019nCoV) outbreak, reported in December 2019 in the Chinese city of Wuhan, presented a challenge to bring together healthcare professionals for interdisciplinary exchange of expertise, response plans, and sharing of concerns.

Materials and methods: The MMA Academy, in collaboration with the Superintendence of Public Health within the Ministry for Health, organised an interactive seminar for healthcare professionals on the 2019-nCoV in February 2020. Information on the seminar was disseminated through the media platforms of the MMA and e-mails to healthcare professionals. Key academic experts in pharmacy, virology, pathology, public health, infectious diseases, and health promotion addressed this seminar in an effort to consolidate a unified information strategy for prevention and control.

Results: Over 100 professionals working in the public and private health sectors participated actively in the seminar, including doctors, dental surgeons, nurses, pharmacists, and medical laboratory scientists. In this seminar were presented science, myths, realities, laboratory testing, clinical diagnosis, infection control, protective exigencies, and the preparedness of the Maltese Health Authorities to counteract this global health emergency. Posters were also distributed to aid in a public awareness campaign through pharmacies and clinics.

Conclusions: Collaboration, training, and effective communication between various healthcare sector disciplines are essential in response to emerging infectious diseases. This interdisciplinary, interactive approach to education can enhance scientific knowledge at an individual level and aid in the development of successful clinical practices and skills. It also helps to integrate knowledge and foster teamwork across various disciplines. 


\author{
Understanding pharmacogenetics and drug \\ interactions through case-based examples \\ L. Mifsud Buhagiar ${ }^{1,2}$, A. Serracino Inglott ${ }^{1,2}$ (D) G. LaFerla ${ }^{3}$ \\ ${ }^{1}$ Department of Pharmacy, Faculty of Medicine and Surgery, \\ University of Malta, Msida, Malta \\ ${ }^{2}$ Medicines Authority, Malta Life Sciences Park, San Ġwann, Malta \\ ${ }^{3}$ Department of Surgery, Faculty of Medicine and Surgery, University \\ of Malta, Msida, Malta
}

Introduction: Pharmacogenetics of drug metabolism is progressing in community and primary care settings, presenting a challenge to integrate applied aspects in pharmacy curricula. Phenoconversion, where the metaboliser status predicted by genotype is altered through drug interactions, is often overlooked, warranting further consideration within pharmacy programmes of study.

Materials and methods: Case studies from 44 patients on amitriptyline, a medicine with established pharmacogenetic connotations, were selected as pedagogical resources to explain drug-gene, drug-drug, and drug-drug-gene interactions. Data included the results of analytical (genetic/chemical) and clinical investigations of patients recruited from Mater Dei Hospital, Malta, following ethics approval and written informed consent. An interactive exercise on three case-based scenarios was integrated into a two-hour seminar delivered to second-year pharmacy students. The teaching model included the presentation of applied biochemistry basics followed by a hands-on understanding of pharmacotherapeutic implications.

Results: In the cases presented, CYP2D6 inhibition by concomitant drugs (particularly paroxetine) was linked to higher-than-expected serum concentrations of amitriptyline and its active metabolite nortriptyline in the recruited subjects, explaining almost $50 \%$ of the variation $(p<0.01)$. Through these case studies, students could identify the impact of genetic variants and the co-administration of CYP inhibitors on drugmetabolising enzyme activity and individual patient outcomes. The seminar evaluation highlighted that the real-case scenarios helped students understand the applied aspects and the fundamental principles of pharmacogenetics.

Conclusions: As the genomics era endures, it is crucial to impart a practical grasp of how clinical pharmacology, embracing real-world patients and the polypharmacy challenge, should complement pharmacogenetics in making precision medicine a working reality. Leveraging research findings from local investigations provides an opportunity for students to learn from examples of familiar therapeutic regimes and clinical settings. A case-based learning experience enables future pharmacists to comprehend the translational value of the field of study, appreciating their prospective role in spearheading effective implementation for patient care.

\section{Proactive support to maximise MPharm student wellbeing and performance: 4 years of impact}

N. Ward

Leicester School of Pharmacy, De Montfort University, Leicester, United Kingdom

Introduction: In 2015, a bespoke wellbeing and support programme was developed in collaboration with student support services to address high levels of MPharm student anxiety and stress (Evans \& Ward, 2018). A range of workshops and resources were designed to address stressors identified by students, anxiety associated with Objective Structured Clinical Examinations (OSCEs), pressures of professionalism, and work-life balance. Subsequently, the programme has evolved to include maths anxiety support. The aims of the programme, which was embedded within professional skills modules, are to improve student wellbeing, develop resilience, and maximise academic performance.

Materials and methods: The programme has been evaluated since its introduction, and to date, over 1000 students have participated. All workshop participants completed evaluation forms, and key themes have been identified from student feedback utilising thematic content analysis.

Results: Of the total students attending the workshops, 92\% would recommend them to their friends, with $96 \%$ gaining a better understanding of how their wellbeing relates to performance, and $96 \%$ learnt helpful strategies for the future. Over the last four years, common themes demonstrating the personal impact of the workshops have been identified, including the importance and relevance of wellbeing ("Important to take care of yourself as a future healthcare professional in order to deliver the best service possible to patients"), the importance of gaining perspective ("To know that the difficult situations have been overcome before"), and identifying personal issues with wellbeing ("I always feel guilty when I'm not studying-now I know that taking time out is actually ok- it is me being a professional").

Conclusions: The programme continues to evolve and develop, and other schools within the institution are recognising the benefits of embedded, bespoke wellbeing initiatives.

\section{Reference}

Evans, M., \& Ward, N. (2018). Building resilience and improving wellbeing in pharmacy students: a collaborative approach. University and College Counselling Journal, 17(1), 173-189 


\section{ADVANCE - A three-stage blended learning programme in the ATMP development}

I. Mlinaric-Rascan ${ }^{1}$, D. Urbancic ${ }^{1}$, B. Bozic ${ }^{1}$, H. Stevens ${ }^{2}$, N. Verdonk $^{3}$, L.Gabriele ${ }^{4}$, I. Huys ${ }^{5}$, L. Aurisicchio ${ }^{6}$, E. Keidong ${ }^{7}$, R. Kreeftmeijer-Vegter ${ }^{7}$

${ }^{1}$ University of Ljubljana, Faculty of Pharmacy, Ljubljana, Slovenia

${ }^{2}$ Université libre de Bruxelles (ULB), Institute for Interdisciplinary Innovation in Healthcare $\left(I^{3} h\right)$, Brussels, Belgium

${ }^{3}$ Elevate B.V., Utrecht, The Netherlands

${ }^{4}$ Instituto Superiore di Sanita, Roma, Italy

${ }^{5} \mathrm{KU}$ Leuven, Leuven, Belgium

${ }^{6}$ Takis SRL, Roma, Italy

'EATRIS ERIC, Amsterdam, The Netherlands

Introduction: Advanced therapy medicinal products (ATMPs) offer unprecedented promise for the long-term management of diseases and even cure, especially in areas of high unmet medical needs. However, the translation from research into patient benefit faces many challenges and requires the involvement of many stakeholders, including academic researchers, start-ups, the biotech industry, regulatory and health technology assessment (HTA) agencies, and patient representatives. ADVANCE is a 30 -month training project supported by the Erasmus+ Programme of the EU to develop a learning programme supporting early-career biomedical scientists in developing a holistic vision of the complex processes and translate scientific advances into patientoriented standards of care.

Materials and methods: The "next generation of ATMP developers" - early-career biomedical academics (PhD, Postdoc) - are the core target group. The three-stage blended learning programme consists of three complementary and interconnected modules, all addressing key challenge areas in ATMP development: (1) an online course for teaching "basic" scientific knowledge; (2) webinars for in-depth scientific knowledge and skills, combined with career coaching; and (3) face-to-face workshops for training transversal skills and competencies.

Results: Both the webinars and the online course will be free of charge and available to a broad audience. The three curricula (1-3) will be complemented by digital credentials and a sustainability plan. The programme aims to enhance the quality of knowledge, transversal skills, and competencies trained, relevant for the biomedical labour market, thereby increasing the employability in the field and fostering the interaction between innovative research and development and education.

Conclusions: The successful implementation of curricula and sustainability-oriented project design anticipates long-term benefits in terms of public health improvements through better-trained professionals who will drive effective and accelerated ATMP development and offer safe and affordable treatment for patients with high unmet medical needs.

This project receives funding from the European Union's Erasmus Plus programme under grant agreement 2019-1-NL01-KA203-060286. This publication reflects the views only of the author, and the Commission cannot be held responsible for any use which may be made of the information contained therein. https://eatris.eu/projects/advance/

\section{Renewal of the competency-based pharmacy curriculum at Utrecht university}

\author{
R.J. Kok ${ }^{D}$, A.K. Mantel-Teeuwisse
}

Department of Pharmaceutical Sciences, Utrecht University, Utrecht, The Netherlands

Introduction: The pharmacy curriculum in the Netherlands is a 6-year programme, equally divided over a 3-year bachelor plus 3-year Master in Science. Both programmes are offered as competency-based curricula in which disciplinary fields have been integrated around disease or context-oriented themes. The Utrecht pharmacy curriculum is research- and profession-oriented and includes a 5-month research internship and a 26-week training in community or hospital pharmacies. Research innovations such as cell and gene therapy and the altered professional landscape of pharmacists demand a continuous renewal of the Utrecht pharmacy curriculum.

Materials and methods: The Utrecht pharmacy curriculum was developed closely with the new pharmacy competency framework for the Netherlands. Learning outcomes of the renewed curriculum were organised around discipline-based (Bachelor) and competency-based themes (Master).

Results: From 2016 through 2019, the new pharmacy curriculum was introduced in both bachelor and master simultaneously, without affecting the enrollment of new students ( $\sim 200$ bachelor students and $\sim 130$ master students annually). Educational concepts such as inquiry-based and experiential learning were introduced, along with a stronger focus on academic and professional skills. The accreditation organisation of the Netherlands and Flanders (NVAO) rated both programmes as 'Good' in 2019.

Conclusions: Utrecht University managed to implement a new competency-based curriculum in a relatively short time frame. As a next step, the performance of students in practice will be surveyed. 


\section{Bachelor's degree final project: An opportunity to explore different career possibilities}

M. Igartua ${ }^{D}$, C. Alonso $(D)$, M. Arroyo-Izaga $(D)$ J. Bikandi ${ }^{(D)}$ J.M. Ezpeleta (D) E. Goicoechea (D), N. Unceta (D)

Faculty of Pharmacy, University of the Basque Country (UPV/EHU), Spain

Introduction: The Bachelor's Degree Final Project (FP) is a compulsory subject of 6 ECTS credits to earn the pharmacy degree at the University of the Basque Country (UPV/EHU). Students must perform an original piece of work that integrates and develops the received training contents, capacities, competencies, and skills acquired throughout the degree (Faculty of Pharmacy, 2019). The Dean's Office that coordinates this subject considers the FP as an opportunity for the students to explore different career possibilities and promotes other modalities of FPs as an alternative to the bibliographical review about a topic. In that case, the FP involves practical work on a topic developed during the compulsory internship period or experimental work carried out within a research group. This strategy is in accordance with some of the cross-curricular competencies defined by the UPV/EHU (Vicerrectorado de Estudiantes y Empleabilidad, 2019).

Materials and methods: The Faculty of Pharmacy reached a large number of agreements with research groups, private companies, and public institutions to achieve this goal. Besides, voluntary internships were promoted for students interested in these new FP modalities.

Results: FPs about topics dealing with the internship period or regarding experimental work increased satisfactorily, being $11 \%$ of the FP defended in the $2015-16$ academic year and $25 \%$ in the 2018-19 academic year. Accordingly, the number of agreements with hosting institutions also increased between 2015 and 2019.

Conclusions: The promotion of innovative FP modalities allowed the students to acquire a broader vision of their professional possibilities, particularly those concerned with their research careers.

\section{References}

Faculty of Pharmacy. (2019). Development Guide of the Bachelor's Degree Final Project. Vitoria-Gasteiz. UPV/EHU [cited 2019 Feb 04]. Available at: https://www.ehu.eus/es/web/farmaziafakultatea/graduamaierako-lana

Vicerrectorado de Estudiantes y Empleabilidad. (2019). Catálogo de competencias transversales de la UPV/EHU. Bilbao: Servicio Editorial de la UPV/EHU [cited 2019 Feb 04]. Available at: https://www.ehu.eus/documents/1432750/12757375/Cat\%C3\%A1l ogo +de+Competencias+trasnversales_cas.pdf/

\section{Establishment of competence centre in personalised medicine: The impact on pharmacy students' education}

B. Pilicheva, P. Zagorchev

Faculty of Pharmacy, Medical University - Plovdiv, Bulgaria

Introduction: There has been a recent interest in competency-based education in health professions education, including pharmacy. This paradigm focuses on creating specialists with competencies that best meet societal needs. Many countries have already adopted competencybased pharmacy education, constructing and implementing of curricula and accreditation criteria of pharmacy programmes. The transformation of traditional pharmacy education into competency-based education offers several advantages but is also associated with substantial implementation challenges. The concept of personalised medicine offers numerous opportunities to pharmacists who have specific knowledge, skills, and abilities that make them uniquely suited to promote the use of personalised medicine as a clinical tool.

Materials and methods: At the Medical University-Plovdiv, a competence centre for innovative personalised medicine (PERIMED) was established in 2018. The competence centre aimed at creating innovative research and educational infrastructure focused on one of the priority axes at the national and European level health-related technologies. The activities at the competence centre are in line with patientcentred health strategies.

Results: Students are involved in research and innovation activities intended for implementation in the field of personalised medicine, with a focus on oncology, oncohaematology, intensive medicine, development of novel drug delivery systems for targeted therapy, bio-engineering technologies, and biosensors. The learning outcomes will be accompanied by promoting research and attracting talented students in the relevant field. Moreover, conditions for scientific capacity improvement will be provided.

Conclusions: Implementation of competency-based pharmacy education is a long-term and complicated process that requires student commitment and institutional stability. All stakeholders involved (teachers, students, and employers) pointed out the need to update teaching practices according to the rapidly developing knowledge in various fields of the pharmacy profession. 


\section{Efficiency of teaching chemical disciplines to pharmaceutical students based on the synergetic approach}

\author{
I. Nizhenkovska(D), O. Kuznetsova(D), V. Narokha (D) \\ Bogomolets National Medical University, Kiev, Ukraine
}

Introduction: The relevance of improving the quality of basic chemical knowledge among students of pharmaceutical specialities is because, in the conditions of modernisation of pharmaceutical education in Ukraine, it is necessary to provide an innovative approach to teaching, taking into account the trends in a modern synergetic paradigm in pedagogy; the priority is to create optimal conditions for personal development.

Materials and methods: The experiment involved 989 second to third year students of the pharmaceutical faculty of the Bogomolets National Medical University in the academic years of 2017/2018 and 2018/2019. Students in the control group received traditional training in Biochemistry, while the study group followed the innovative teaching system. During the fourth and fifth terms, knowledge checks and various types of written works were systematically performed. Students' satisfaction with classes and teaching technologies was assessed using the CSI (customer satisfaction index) method. At the end of the course and after testing and questioning students, analyses of the level of biochemical knowledge formation were carried out, i.e. the coefficient of course content mastering was calculated. The efficiency coefficient for innovative technologies was computed by summing the mastering coefficient and the student satisfaction index. The following study methods were used: testing, questioning, and methods of mathematical statistics.

Results: The analysis of the results showed the following: 1) The level of knowledge formation was $0.855 \pm 0.025$ in the study group and $0.65 \pm 0.01$ in the control group. The mastering coefficient was higher in the study group than the control group, by an average of 0.2 at the end of the fourth term and 0.22 at the end of the fifth term. 2) The satisfaction index was higher in the study group compared to the control group by an average of 0.191 . 3) The efficiency coefficient for innovative teaching technologies was higher than the efficiency coefficient for traditional technologies by an average of 0.197 .

Conclusions: Implementing a synergistic approach, i.e. updating the contents, methods, and forms of training, taking into account factors such as openness, self-organisation, selfdevelopment, nonlinear thinking, management, and selfmanagement, improves the quality of teaching chemical subjects to students in pharmacy training.

\section{Development of pharmaceutical care practical skills during pharmacy internship}

V. Bobrova, D. Volmer

University of Tartu, Tartu, Estonia

Introduction: Pharmaceutical care (PC) is the identification, resolution, and prevention of potential drug-related problems. It is essential to develop PC practical skills to secure quality provision of care. In the pharmacy curriculum at the University of Tartu, the content of the six-month pharmacy internship was redesigned in 2017 to provide a practice more focused on PC. This study aimed to evaluate the implementation of the redesigned pharmacy internship by outcomes associated with pharmacy students' experience in the provision of PC.

Materials and methods: The study sample consisted of fifthyear pharmacy students who completed the pharmacy internship in 2018 and 2019 ( $n=45)$. An international 20-item survey instrument (1) was adapted. Students' perceptions of PC skills (ten items), functions (five items), and outcomes (five items) were collected before and after the pharmacy internship, using a five-point Likert scale (1=strongly disagree to $5=$ strongly agree). For data analysis, the Mann-Whitney test was used.

Results: Statistical comparison of pre-internship and postinternship evaluation results demonstrated that perception of most of the survey items was significantly improved after the pharmacy internship. The mean score of perception about PC skills was $3.44 \pm 0.34$ in the pre-test and $4.38 \pm 0.29$; $p \leq 0.01$ in the post-test. Among PC functions, identification, understanding, and solving drug-related problems improved (all $p=0.01$ ). Students perceived their increased role in improving patient quality of life and reducing treatment costs ( $p=0.01$ for both).

Conclusions: According to their perception during the pharmacy internship, students' PC practical skills have significantly improved. Results demonstrate that the updated pharmacy internship course has been successfully implemented. 


\section{Eye and click tracking to evaluate engagement in computer-based simulation}

\author{
D. L. Hope ${ }^{1}$ (D) G. D. Grant ${ }^{2}$ D
}

${ }^{1}$ School of Pharmacy and Pharmacology and Quality Use of

Medicines Network, Griffith University, Gold Coast, Australia

${ }^{2}$ School of Pharmacy and Pharmacology and Quality Use of Medicines Network, Griffith University, Gold Coast, Australia

Introduction: Student engagement represents the time, involvement, and quality of effort invested in productive learning activities and is closely linked to the cognitive aspects of learning. Computer-based simulation provides replicable, cost-effective learning approaches in safe environments. Student engagement with computer-based simulation may be challenging to assess. Eye-tracking performance has been linked to engagement of attention, and recent affordability of equipment, such as Gazepoint hardware and software, allows for physiological engagement to be investigated. This study aimed to explore the feasibility of using eye and click tracking to evaluate engagement in a computer-based simulation.

Materials and methods: The feasibility study employed Gazepoint gaze tracking equipment during a computer-based simulation based on a community pharmacy request for emergency contraception. The simulation used digital avatars for the patient, pharmacist, and doctor with audible questions and responses. Participants flexibly navigated the simulation and received feedback from the pharmacist avatar. Physiological engagement during the simulation was recorded using the Gazepoint video-based eye tracker and post-analysis of the recorded mouse tracking and clicks.

Results: Twelve third-year pharmacy students participated. The Gazepoint data recordings for the entire simulation were reviewed by two observers. Participants' eye tracks were displayed as heat maps or fixation maps and identified areas of interest and time spent on task. Most participants showed engagement with the simulation, with $83 \%$ focused on the patient avatar when speaking. Participants' navigation and directional choices in the simulation were accurately determined by observation of mouse movement and clicks. An outcome of this study is the suggestion that future simulation design might consider operation within a standardised screen to enable calibration in the timing of participants' gaze fixations.

Conclusions: Gazepoint eye and click track recordings showed promise in identifying students' physiological engagement during computer-based simulation. Participants' navigational choices could inform future simulation development.

\section{Ecological momentary assessment in a gamified simulation}

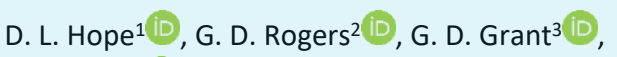 \\ M. A. King 4
}

${ }^{1}$ School of Pharmacy and Pharmacology and Quality Use of Medicines Network, Griffith University, Gold Coast, Australia

${ }^{2}$ School of Medicine and Griffith Health Institute for the Development of Education and Scholarship (Health IDEAS), Griffith University, Gold Coast, Australia

${ }^{3}$ School of Pharmacy and Pharmacology and Quality Use of Medicines Network, Griffith University, Gold Coast, Australia

${ }^{4}$ School of Pharmacy and Pharmacology and Quality Use of Medicines Network, Griffith University, Gold Coast, Australia

Introduction: The perceived stress of health professional students influences their confidence and motivation to learn. An extended gamified simulation was developed as a capstone learning experience in a Bachelor of Pharmacy programme, designed to provide engaging real-world practice experience. Students competed in teams, assumed the pharmacists' roles, and were responsible for all patientcentred outcomes, as determined through continual assessment. Such high-stakes and intensive activities have the potential to induce student stress. This study aimed to use ecological momentary assessment (EMA) to capture real-time student experience and behaviours during the simulation, limiting recall bias (Stone \& Shiffman, 1994).

Materials and methods: Student participants completed periodic EMAs during the three-week gamified simulation. Five participants per day received digital prompts to undertake EMA in Microsoft Forms. Each EMA involved selfreporting momentary stress on a five-point Likert scale from 1 (not at all) to 5 (extremely), recording the preceding activity in free text and selecting their degree of physical activity (sedentary, light activity, or moderate-to-vigorous activity). Pearson's Correlation analyses were conducted in SPSS 22.

Results: In total, 355 EMAs were completed by 28 students. Activities recorded were coded into seven groups: administrative, verbal, dispensing, clinical case, team discussion, observation, and non-cognitive. The highest selfreported stress was associated with verbal activities, which included simulated patient counselling and clinical telephone calls. While there was no significant relationship between stress and gender, day, or week of the game, student stress had a small positive correlation with simulation activity $(r=$ $0.262, p<0.01)$ and a moderate correlation with the level of activity $(r=0.320, p<0.01)$.

Conclusions: Using EMA provides a valuable, non-invasive way to determine student stress and has the potential to identify students at risk. The method would suit repeated measure studies.

\section{Reference}

Stone, A. A., \& Shiffman, S. (1994). Ecological Momentary Assessment (Ema) in Behavioral Medicine. Annals of Behavioral Medicine, 16(3), 199-202. https://doi.org/10.1093/abm/16.3.199 


\section{Pharmacy students' opinion about the objective structured clinical examination (OSCE) in Poland}

J. Dymek, A. Gołda, W. Polak, M. Jachowicz, T. Kowalski, A. Skowron

Department of Social Pharmacy, Faculty of Pharmacy, Jagiellonian University Medical College, Kraków, Poland

Introduction: In the last decade, OSCE was widely implemented into the pharmacy curricula worldwide. Our team developed OSCE as a final exam in the Pharmaceutical Care course for fifth-year pharmacy students. This study aims to compare the opinion of pharmacy students with the results of the exam.

Materials and methods: A self-administered structured questionnaire was used to obtain opinions about the exam of respondent students who took their OSCE exam for the first time. The questionnaire was administered just after they finished the exam. All students were informed that the survey was anonymous and voluntary and that they had the right to refuse to participate.

Results: Almost $95 \%$ of students admitted that information about the organisational aspect of the exam and instructions at individual stations were understandable. Most students indicated the station 5 (identification of DRP) was the one on which they will get the worse grade, and about half of respondents reported the same station as the most stressful. The less stressful station reported by most students was station 1 (patient interview), where they expected to receive the best grades. The analysis of OSCE results showed that the best average grade $(>73 \%)$ was observed at station 3 (education about medicine), indicated by less than half of respondents as the one where they expected the best grade. The worse results (average grade $<60 \%$ ) were seen at station 5 , as predicted by students.

Conclusions: Students were positive about the organisation of OSCE and found that it simulated quite well the professional situation. The actual and projected results of the exam were only partly consistent, which may indicate that students are not able to self-assess the level of competencies and compare it with the expectations of their future employer.

\section{Evaluation of Erasmus experience for pharmaceutical technology students}

N. Sammut Bartolo , J. Vella Szijj, F. Wirth (D),

LM. Azzopardi ${ }^{D}$

Department of Pharmacy, University of Malta, Msida, Malta

Introduction: During the third year of studies, students reading for a Bachelor's Degree in Pharmaceutical Technology have the opportunity to carry out an eight-week placement at a European university under the Erasmus programme. During this period, students participate in research projects in university laboratories. They are followed up virtually by tutors from the sending institution to support them to develop learning skills during the placement.

Materials and methods: A self-administered questionnaire was disseminated to pharmaceutical technology students to evaluate their Erasmus experience. The questionnaire consisted of ten closed-ended five-point Likert scale items, ranging from strongly agree to strongly disagree. The questionnaire assessed how the experience helped students develop, in what aspects did the tutors from the sending institution help during the virtual tutorials, and whether they would recommend the experience to other students.

Results: Of the ten (out of 11) students in third-year Pharmaceutical Technology enrolled in the Erasmus programme during the scholastic year 2019/2020; seven answered the questionnaire. Participants agreed that the Erasmus experience helped them to develop academically $(n=6)$ and personally $(n=6)$, gain $(n=6)$ and improve $(n=5)$ laboratory skills, and extend their network of fellow students and friends $(n=4)$. Students agreed that tutorials helped in guiding them to keep records of daily activities $(n=3)$ and that tutors helped with logistical $(n=4)$, academic $(n=4)$, and personal $(n=3)$ issues experienced during the Erasmus internship. All students agreed that, when given a choice, they would recommend this experience to other students.

Conclusions: The Erasmus experience enables students to develop academically and personally. The tutorials can be further structured based on the findings of this study to standardise the support provided to all students following a mobility placement. 


\section{A common training framework for hospital pharmacy in Europe}

P. Horák ${ }^{1,3}$, J. Peppard1,3, G. Marzal ${ }^{3}$, S. Kohl ${ }^{3}$

${ }^{1}$ University Hospital Praha, Motol, Czech Republic

${ }^{2}$ Midland Hospital Regional Tullamore, Ireland

${ }^{3}$ European Association of Hospital Pharmacists (EAHP), Brussels, Belgium

Introduction: The aim of the Common Training Framework (CTF) for hospital pharmacy is to achieve automatic professional qualification recognition for hospital pharmacists across EU countries, meaning that learning outcomes and competencies received by specialisation in hospital pharmacy in one European country will be recognised throughout Europe. The CTF for hospital pharmacy would achieve four key benefits in Europe: the patient benefit, improving labour mobility and the benefits that arise from that, a benchmark for all European countries to strive for, and a vital strategic tool for realising the European Statements of Hospital Pharmacy adopted in 2014.

Materials and methods: 1) Development of a framework via a working group consisting of hospital pharmacists from across Europe; 2 ) Review of the framework through an online Delphi consultation involving other healthcare professionals; 3) Creation of three Working Groups and a steering committee to work on the project; 4) Engage with national authorities and relevant stakeholders to obtain their support for the project; 5) Creation of a project plan to make CTF a reality.

Results: The European Association of Faculties of Pharmacy (EAHP) adopted a final framework in 2017 containing 24 competencies, 87 knowledge items, and 136 behaviour competencies. EAHP has support from all its 35 national member associations (via endorsement letters). The first CTF Meeting of national authorities took place at the $24^{\text {th }}$ EAHP Congress in Barcelona (March 2019). EAHP has gathered relevant information on the national hospital pharmacy specialisations programme and developed a project plan to move forward, including the development of a CTF roadmap.

Conclusions: The CTF Project (reflecting national and regional realities) meets the need identified for training in competencies required to achieve the level of practice identified in the European Statements of Hospital Pharmacy, which will lead to improved patient care. Additionally, the free movement of specialised hospital pharmacists will be enabled.

\section{The curricula mapping for ethics and legislation topics in pharmacy and laboratory biomedicine programmes at faculty of pharmacy university in Ljubljana}

B. Božič, A. Obreza, J. Omersel, A. Šmid, T. Vovk

University of Ljubljana, Faculty of Pharmacy, Ljubljana, Slovenia

Introduction: University programmes are moving towards a quality system based on competencies to meet public expectations. The Faculty of Pharmacy in Ljubljana runs 2 Master's programmes, i.e., Pharmacy - PHAR (5 years) and Laboratory Biomedicine - LBM ( $3+2$ years). Both profiles are expected to work in the health care system and perform demanding tasks related to patient care. As such, faculty programmes should develop ethically minded professionals with an appropriate level of regulatory understanding.

Materials and methods: Two rounds of the Delphi method were used by a group of five experts involved in both programmes. Curricula, as written in the accreditation documents, have been reviewed for ethics and ethics-related legislation topics. A five-point Likert scale was used for the evaluation $(0=$ not covered at all, $1=$ poor, $2=$ fair, $3=$ good, and $4=$ very good). A consensus was reached during the second round.

Results: Searched topics were written in 14 out of 59 syllabuses of PHAR and nine out of 57 syllabuses of LBM programme. The consensual evaluation showed that topics were rated "very good" in one PHAR and two LBM courses, "good" in one PHAR course, "fair to good" in one LBM course, "fair" in four PHAR courses, "poor to fair" in two LBM courses, and "poor" in nine PHAR and four LBM courses. Among PHAR courses, six were mandatory and eight electives, ranging from 3-30 ECTS, but mainly five ECTS. Among LBM courses, five were mandatory and four electives, in the range of 3-14 ECTS.

Conclusions: The simultaneous mapping of PHAR and LBM programmes showed that ethics and legislation-related topics are well covered in both programmes. This study is only the first step of the evaluation. Comparison of intended, perceived, and achieved competencies as evaluated by students, graduates, teachers, and employers would be very beneficial to improve the programmes and their performance. 


\author{
Digital gaming in teaching pharmacy vocabulary \\ H.G Mercanoğlu1 (D), H.G Yüksel \\ ${ }^{1}$ Faculty of Pharmacy, University of Health Sciences, istanbul, Turkey \\ ${ }^{2}$ Faculty of Education, Yıldız Technical University, istanbul, Turkey
}

\section{Universalut health fair: An effective experiential teaching method}

\author{
J Pereda (D), ML Ferrándiz ${ }^{(D)}$, H Rico ${ }^{(D)}$, TM Garrigues $(D)$
}

Faculty of Pharmacy, University of Valencia, Spain
Introduction: Given the crucial role of technical vocabulary knowledge for subject learning in pharmacy education, there is a need for efficient technical vocabulary teaching approaches. However, at tertiary level classes, the motivational aspect is mainly ignored. It was hypothesised that integrating digital game-based activities into the classroom may provide learners with a positive learning experience that can increase their learning. This study investigates the influence of in-class digital game-based activities on pharmacy students' technical vocabulary learning performance and explores their perceptions.

Materials and methods: This experimental study compared two vocabulary teaching approaches (in-class digital gaming and no in-class digital gaming), targeting 400 technical vocabularies. A sample of 47 second-year pharmacy students participated in the study over 15 weeks (experimental group=21; control group=26). Data were collected through two vocabulary tests and a 12 -item questionnaire developed by Dizon (2016) based on the technology acceptance model (TAM).

Results: A Mann-Whitney $U$ test showed no significant differences between the experimental and control groups, both in the first $(U=101.5, p=0.000)$ and second vocabulary test scores $(U=153.5, p=0.010)$. The calculated effect sizes were 0.536 and 0.378 , respectively. This finding suggests that in-class digital gaming has a moderate to large effect on technical vocabulary learning. The results of the questionnaire indicated that students had positive perceptions about the digital tool used.

Conclusions: In short, in-class digital gaming showed to be a helpful approach to learning technical vocabulary, as indicated by the significant differences found in the vocabulary test scores between the experimental and control groups. Equally important is the finding that the level of perceived usefulness was higher in the experimental group, suggesting that in-class experience influences technology acceptance and use behaviours in tertiary-level learners.
Introduction: There is a clear need for hands-on learning that confronts our students with real-life situations. With Universalut, a health fair prepared ad hoc; students were set in a real-life environment in contact with citizens to put into practice the acquired competencies. Moreover, the university approaches society, spreading healthy lifestyles among the population.

Materials and methods: The Faculty/University services contacted the council of Valencian Community cities to organise a health fair. It consisted of several workshops for adults and children, showing some professional services of pharmacists. The city council provided urban furniture and a safe environment. The volunteer staff was involved in the supervision of the preparation and actual performance of workshops carried out by students. The students voluntarily enrolled and received 1.5 ECTS for participating. The workshops preparation and materials involved different teaching-learning methods, such as role-playing, design of infographics, reflecting on contents, with a high impact on motivation. Students from other health science majors were also invited to participate to promote teamwork and interdisciplinary learning.

Results: The project began in the 2018-2019 course with two health fairs. On the $8^{\text {th }}$ of April 2019, around 40 students and seven professors made Universalut possible in Ontinyent. On the $13^{\text {th }}$ of April 2019, 70 students and 11 teachers participated in Villar del Arzobispo, where companies and associations joined. Pharmacy students carried out 11 different workshops, while Human Nutrition and Dietetics students performed seven, and Food Sciences students another seven. During 2019-20, three cities expressed interest in receiving Universalut and took the compromise. A total of 136 pharmacy students enrolled for the training stage.

Conclusions: Universalut promotes learning while transmitting evidence-based health education, bringing the university closer to society. Universalut participants are highly satisfied with the outcomes. 


\author{
Simulation-based blood pressure measurement \\ training for pharmacy students \\ F. Wirth ${ }^{D}$, P. Falzon, L.M. Azzopardi \\ Department of Pharmacy, Faculty of Medicine and Surgery, \\ University of Malta, Msida, Malta
}

Introduction: Simulation-based training is an educational technique that complements didactic teaching to support the development of necessary clinical skills and competencies for pharmacy students before completing their professional training. The aim was to evaluate the perception of pharmacy students of simulation-based blood pressure (BP) measurement training.

Materials and methods: BP measurement simulation involves having an arm anatomically similar to that of a human being, allowing a student to practice the same skills and techniques in measuring BP as executed on a human subject. Systolic and diastolic BP and volume settings are adjusted using an external control panel allowing for variability as seen in clinical practice. An evaluation questionnaire consisting of ten five-point Likert-type questions (strongly disagree to strongly agree) was disseminated to all 22 first-year undergraduate pharmacy students after the practical session using the BP simulator. Descriptive statistics were calculated.

Results: 20 students, 16 females and four males (mean age 20.5 years, range $18-30$ years), completed the questionnaire. All students agreed that the BP training simulator promoted innovative and interactive learning and enhanced their learning experience. Furthermore, 19 agreed that the simulator is an effective teaching tool that will impact their future practice positively, 19 would recommend the use of a simulator in future experiential sessions. Students agreed that the simulator promoted self-confidence in the technique in real-life situations $(n=18)$, helped to transform theoretical knowledge into clinical skills $(n=18)$, helped to identify challenges in the technique before actual practice $(n=16)$, was realistic $(n=16)$, and user-friendly $(n=15)$.

Conclusions: The simulation-based BP measurement training promoted confidence among first-year students reading for a pharmacy degree before they embark on real-life blood pressure measurement scenarios in patients.

\section{A pharmacy graduate perspective of the involvement of patients and carers in the design and delivery of the pharmacy undergraduate curriculum}

T. Jebara1 $^{(D)}$, R. Edwards $^{2}$ (D), AP. Tonna ${ }^{(D)}$

${ }^{1}$ Robert Gordon University, Aberdeen, Scotland, United Kingdom

${ }^{2}$ Aston University, Birmingham, United Kingdom

Introduction: There is increasing support for active teaching by involving patients and carers in health-related undergraduate teaching. Within pharmacy, the aim is for patients and educators to work synergistically to improve the learning and teaching of future pharmacists. The School of Pharmacy and Life Sciences (PALS) has been reviewing teaching of undergraduate students to involve patients and carers sharing their experiences about their condition in a fourth-year module. This study aimed to evaluate this innovative teaching method within pharmacy education by exploring pharmacy graduates' perspectives of the involvement of patients and carers in the design and delivery of the pharmacy curriculum.

Materials and methods: This study utilised semi-structured telephone interviews with recent PALS graduates who had provided their contact details prior to completing their studies and consented to participate. The interview schedule was developed based on the research aim, an extensive literature review, and peer discussion, then piloted to ensure its credibility and validity. Interviews were recorded and transcribed verbatim. Thematic analysis was conducted independently by two researchers to identify key themes.

Results: All 13 participants interviewed had an experience of active teaching. Many highlighted the need for more sessions involving active teaching in undergraduate studies. They perceived this as a way to improve their learning by complementing the topics delivered using more traditional teaching methods. This method also allowed them to apply their knowledge and skills better, thus better equipping them and providing them with more relevant information for practice. However, pharmacy graduates were uncertain about patient and carer involvement in the design of the pharmacy undergraduate course.

Conclusions: Pharmacy graduates positively viewed patients' and carers' active involvement within the pharmacy curriculum and highlighted many benefits, such as consolidating learning. In view of this evidence, it is planned to further embed active teaching within the pharmacy curriculum. 


\section{5 years of the faculty of pharmacy of the medical university of Lublin: The pillar of pharmacy education in eastern Poland}

\section{G. Biala, A. Malm}

Faculty of Pharmacy, Medical University of Lublin, Poland

Introduction: The Faculty of Pharmacy of the Medical University of Lublin was created in 1945. It has a long tradition in teaching pharmacy and disseminating knowledge in the field of pharmaceutical sciences. With its significant scientific effectiveness, it is recognised as the leader among faculties of pharmacy in Poland with the highest A+ category.

Materials and methods: First, the mission and the faculty's development strategy have been specified, after public consultation, the work of appointed committees, and with the consent of academics and students. Second, results of the annual ranking of The Centre for Science and Technology Studies, University of Leiden, the Netherlands, which assesses universities' scientific performance based on bibliometrics, were mentioned. For the first time, it included a gender balance metric that calculates the proportion of women among the number of paper authors.

Results: 1) The mission of our faculty includes conducting scientific activities and educating students while maintaining the principle of compliance of science and didactics and constant improvement of the quality of teaching together with the dissemination of knowledge in the field of pharmaceutical sciences. 2) The faculty's development strategy includes the diversity of study programmes, openness to the socioeconomic environment, mobility of academic staff and students (about 20 Erasmus Plus agreements), leading to strengthening the faculty's position. 3) The Medical University of Lublin, especially the Faculty of Pharmacy, obtained the highest rate of scientific works, whose authors are women (56\%) according to the annual Leiden ranking.

Conclusions: Among the strengths of the faculty are relatively young teaching and research staff consisting mainly of pharmacists, women in principle, high quality of education, effectiveness in research grants in the domain of pre-clinical drug testing. The faculty can be considered the pillar of pharmacy education in Eastern Poland.
International Pharmaceutical Federation (FIP): Uniting science, practice, and education to improve global health

R. J. Altiere ${ }^{1,2}$, L.M. Azzopardi ${ }^{1,3}$ (D) P. Moreau ${ }^{1,4}$, N. Uzman ${ }^{1}$

${ }^{1}$ International Pharmaceutical Federation (FIP)

${ }^{2}$ University of Colorado Skaggs School of Pharmacy and Pharmaceutical Sciences, Aurora, Colorado, United States

${ }^{3}$ University of Malta, Department of Pharmacy, Msida, Malta

${ }^{4}$ Kuwait University Faculty of Pharmacy, Kuwait

Introduction: Under the new leadership of Catherine Duggan, CEO, and Dominique Jordan, President, FIP has developed a renewed vision, mission, strategic plan, and global development goals that will be shared in this presentation. Under the moniker of "One FIP," FIP is the only international organisation that combines science, education, and practice under one roof.

Methods and results: To solidify its unique role, FIP is creating close partnerships with WHO, UN, WHPA, Bill and Melinda Gates Foundation, and World Bank to champion universal health coverage and primary health care from prevention to NCDs management to innovation using the combined three assets of One FIP. FIP embarked on regional conferences with member organisations to broaden its global impact, the first in Amman, Jordan, for the EMR, and a second in Ankara, Turkey, for the European Region, with additional conferences scheduled in the years ahead. During the Ankara Conference, EAFP contributed to a session to reflect on pharmacy education that empowers graduates who can merge science with practice to contribute to the advancement of pharmaceutical services. Within the context of pharmaceutical needs, recognising the impact of technology on pharmacy and healthcare is becoming more and more of an urgent priority. To address this emerging need, a new Technology Forum was established within FIP, and the theme of the 2020 Seville Congress was to specifically address the Technological Revolution and its Impact on Pharmacy and Health Care but was postponed to 2021 due to the COVID-19 pandemic. In its place, FIP delivered the FIP Virtual 2020 conference. Of particular interest to EAFP members was the virtual AIM Global Academic Leaders Forum (GALF). A new initiative was launched at virtual GALF 2020 to promote leadership development in academia. AIM, together with AACP, established the Global Academic Leadership Fellows Program to develop emerging academic leaders to be launched in 2021. FIP AIM delivered an abbreviated online version of this leadership programme, the first session presented at the virtual 2020 GALF with three other sessions available asynchronously via the FIP website.

Conclusion: By establishing these collaborative networks, FIP becomes an international driving force supporting the achievement of better outcomes, with a high impact on advancing pharmacy worldwide. 


\section{Participation in the university introduction day is essential for the recruitment of pharmacy students in Iceland}

B.E. Benediktsdóttir ${ }^{1,2}$ (D) H.H. Sigurđsson ${ }^{1}$ (D)

${ }^{1}$ Faculty of Pharmaceutical Sciences, University of Iceland, Reykjavik, Iceland

${ }^{2}$ Biomedical Centre, University of Iceland, Reykjavik, Iceland

Introduction: The university introduction day (UID), where all universities in Iceland advertise their study programmes, is held yearly for all potential students. The pharmacy programme (BS and MS degrees) is only taught at the University of Iceland within the Faculty of Pharmaceutical Sciences. Advertisement of this study programme, such as at the UID, is the responsibility of the faculty's study board. The success of student recruitment during this UID being unclear, the study board was prompted to analyse why students chose this study programme and whether the UID aided in their decision.

Materials and methods: First-year students enrolled in the BS pharmacy programme autumn 2019 were asked to participate in an online questionnaire during the orientation week. Specific and open-ended questions were asked relating to why they chose this study programme and if they attended the UID.

Results: Out of 44 students enrolled in the pharmacy programme, $28(63.4 \%)$ participated in the survey. Of all participants, $92.8 \%$ were starting their first-year university programme, of whom $61.5 \%$ attended the UID. Interestingly, over $35 \%$ of the participants had a friend already enrolled in the pharmacy programme, showing that the influence of other students is crucial and perhaps underestimated. The main reason why students chose this programme was that they considered pharmacy to be a topic of interest with good job prospects after graduation. Many participants also answered that they chose this field of study due to their interest in chemistry.

Conclusions: Although the recruitment rate has never been a concern for the faculty, the advertisement of the pharmacy programme is essential for attracting students to the programme. The presence of pharmacy students and faculty members at the UD seems to be significant, as over half of the study participants had attended the UID.

\section{Innovative teaching methods in Tallinn health care college}

L.Parts

Tallinn Health Care College, Tallinn, Estonia

Introduction: Tallinn Health Care College (THCC) is a higher education institution offering training in the field of health in Estonia. The year 2015 has opened opportunities for implementing novel teaching methods in THCC. Based on the needs of the Assistant Pharmacist curriculum, the innovative modern laboratories and simulation training facilities were supported by the EU funding measure "Modernisation of the infrastructure of applied higher education and teacher training". Through innovative methods, students are involved through problem-based and simulation-based training in several real-life situations faced by pharmacists in their daily work, preparing them to apply their academic knowledge while working.

Materials and methods: In 2016, new laboratory and simulation training facilities with a pharmaceutical profile were opened, allowing new playful and learner-oriented methods to be integrated into studies at a study-pharmacy, a laboratory of analytical chemistry, rooftop garden, and an elearning environment.

Results: The use of innovative methods has produced good results. Students' desire to participate in projects has increased. Studying at the rooftop garden with interactive tags is a great way to learn phytotherapy. Moreover, students can consolidate their knowledge by studying plant composition in microscopy and instrumental analysis laboratories. Practical learning is also supported by the integration of e-learning environments and tools into several subjects. Many experiential graduation theses have been carried out, and students have won prizes for their research studies. Positive feedback has also come from employers.

Conclusions: The use of innovative teaching methods in the pharmacy assistant curriculum has the potential to raise students' motivation and learning skills. It provides better opportunities for a more diverse pharmaceutical education, broader mind and critical thinking in pharmacy education. It also motivates students to pursue their studies further. 


\author{
Public perception of pharmacists as immunisers \\ K. Eha
}

Tallinn Health Care College, Tallinn, Estonia

Introduction: The profile of services provided at pharmacies is constantly changing. For decades, pharmacists have not been merely dispensing medicines but providing additional services to patients and society. Pharmacy is very often the first encounter with health care services for patients, and in peripheral regions, it might be the only place to get medical advice. Research has shown that patients perceive pharmacists as respected specialists with sufficient knowledge and are pleased with additional services, such as monitoring health indicators, speed tests, counselling, and immunisation. The Estonian influenza vaccination coverage in 2017 was 4\%, being the lowest in the European Union.

Materials and methods: The survey was conducted during two weeks within the vaccination pilot project in October and November 2018 at six different pharmacies in Tallinn, Estonia. It consisted of 22 questions and was voluntary and anonymous, including only adult patients vaccinated at pharmacies. The data were collected using the E-Formular database interface or paper questionnaires, according to participants' preferences. Descriptive statistics were used to analyse the data.

Results: During the first pilot project, 248 participants participated in the survey. Half of them were vaccinated against influenza for the first time. Also, $98 \%$ considered pharmacy a suitable facility for vaccination, $88 \%$ would accept pharmacists as immunisers, and $95 \%$ would vaccinate in pharmacies. Although $69 \%$ declared that immunisation services are easily accessible without pharmacies, they chose to be vaccinated at pharmacies, and $43 \%$ considered visiting a physician inconvenient during working hours.

Conclusions: The Estonian public is interested in accessing vaccination services via pharmacies. Pharmacists are perceived as trustworthy health care workers who should possess the permit to vaccinate. Influenza vaccination coverage in Estonia was significantly improved due to the pilot programme.

\section{Attitudes of Estonian pharmacists about pharmacy-led vaccination programmes}

A. Voronova, K. Nõlvak, R. Surva, T. Must, K. Eha

Tallinn Health Care College, Tallinn, Estonia

Introduction: Estonia has the lowest flu vaccination coverage in the EU. Many countries have improved vaccination coverage by including pharmacists as immunisation providers. This study aimed to determine the readiness of Estonian pharmacists to provide vaccination services in pharmacies and identify the needs of self-reported in-service training of pharmacists.

Materials and methods: The survey was conducted two months after the "Vaccination pilot project at pharmacies" among employees of the four largest pharmacy chains in Estonia. It used an online questionnaire, i.e. e-Formular, which consisted of 29 multiple-choice, open-ended, and scaled questions. Descriptive statistics were performed to analyse the data, and e-Formular was used for the primary statistical analysis of the characteristics. Data analysis described the association with background variables, such as age, gender, length of service, vaccination attitudes, among others. Participation in the survey was voluntary and anonymous.

Results: A total of 313 pharmacists participated in the survey. Most pharmacists were not ready to provide vaccination services themselves at the pharmacy. The underlying reasons for opposing vaccination were lack of appropriate training, lack of time and/or space, unwillingness to touch patients or get in contact with blood, excessive workload and responsibilities, and lack of interest and competence. At the same time, many respondents noted that the availability of adequate training programmes would encourage them to provide vaccination services.

Conclusions: It is necessary to develop a training programme that gives all the required knowledge and skills for immunisation to involve pharmacists in the provision of vaccination services in pharmacies. 


\section{A study of pharmacy-based tick-borne encephalitis vaccinations}

\author{
A. Asu, T. Hirvlaan, M.B. Niitvägi, K. Eha \\ Tallinn Health Care College, Tallinn, Estonia
}

Introduction: Tick-borne encephalitis (TBE) is a viral disease that can damage the central nervous system and cause neurological disorders, with symptoms including nausea, hearing loss, paralysis, and disruption of balance and memory. Over 10,000 patients are hospitalised annually as a result of contracting $T B E$, and the only effective prevention method is vaccination. Offering vaccinations in pharmacies increases the amount of protection against illness as pharmacies can be more convenient and accessible for the patient.

Materials and methods: The survey was conducted for two weeks within the TBE vaccinations in May 2019 at three pharmacies in Tallinn that participated in the 2019 TBE campaign. The survey consisted of 13 multiple-choice and scaled-response questions; it was voluntary and anonymous and included only adults actively receiving vaccination at the participating pharmacy.

Results: Of the 103 participants, approximately $50 \%$ had not received the TBE vaccination before, and $28 \%$ had used the pharmacy vaccination services before. Also, $38 \%$ of surveyed individuals indicated that vaccination services are more accessible at a pharmacy, and almost half of respondents said that visiting the doctor's office is problematic during working hours. Nearly all (99\%) participants consider the pharmacy vaccination services necessary and would use these services in the future.

Conclusions: It is essential to broaden vaccination services across all pharmacies to increase the accessibility of vaccines, raising additional awareness on the impact and preventative measures against infectious disease. Pharmacies can have a vital role in vaccination campaigns and raising awareness among the public on the benefits and availability of vaccinations for diseases such as TBE.
Pharmacists' perception of electronic cigarettes: A quantitative study at community pharmacies in Selangor

M.F.D. Bacayo D. S. Gunalan, M.N.A. Ghani, F. Asmani, J. Khan

School of Pharmacy, Management \& Science University, Selangor Malaysia

Introduction: Electronic (e-) cigarettes, popular batterypowered devices mimicking conventional cigarettes, are widely used by Malaysians. Pharmacists have a role to play in educating people about the safety and effectiveness of ecigarettes. This study aimed to determine community pharmacists' knowledge, attitude, and perception towards ecigarettes.

Materials and methods: This quantitative study involved community pharmacists in the State of Selangor. The adopted questionnaire was distributed to the respondents who were chosen randomly by visiting community pharmacies around Selangor.

Results: Most respondents (97.9\%) are aware of e-cigarettes. As for their perception of e-cigarette use among Malaysians, pharmacists rated 'to help quit smoking conventional cigarette' (43.3\%) and 'to be used socially or recreationally' (42.3\%) as equally 'important'. Most of them agreed that informative awareness campaigns should be conducted on the pros and cons of e-cigarettes (49.5\%), thus agreed to volunteer themselves to participate in the awareness campaign (64.95\%). As for the effectiveness of e-cigarettes, the majority of respondents reported it as 'moderately effective' (44.3\%). Regarding the safety aspect, most pharmacists disagreed that e-cigarettes do not cause any adverse effect (75.3\%). Pharmacists indicated it is crucial for patients on e-cigarettes to have counselling (73.2\%), and they raised concerns on the safety of e-cigarettes, especially the toxic level of e-liquid.

Conclusions: The study was carried out to explore the perception of community pharmacists of the safety, use, and effectiveness of e-cigarettes. The perception of community pharmacists of e-cigarettes was based mainly on ensuring the utmost care and safety for their patients. For this reason, training for pharmacists pertaining to e-cigarettes is recommended. 


\section{Development of an analytical method for the simultaneous determination of glycopeptides, vancomycin, and teicoplanin using high- performance liquid chromatography coupled with mass spectrometry in human urine}

M. Giakoumaki (D) E. Hapeshi

University of Nicosia, Nicosia, Cyprus

Introduction: Vancomycin and teicoplanin belong to the glycopeptide class, remaining high on the list of antibiotics for treating bacteria-resistant hospital infections. The present study aimed to develop an analytical method using HighPerformance Liquid Chromatography (HPLC) coupled with Mass Spectrometry (MS) to determine these two compounds simultaneously in biological fluids, particularly human urine.

Materials and methods: Several chromatographic parameters were examined for the development and optimisation of the analytical method for the determination of the two compounds, such as the type and temperature of column, the type and flow rate of mobile phase, the type of elution, the gradient elution system, and the selection of the desired ion fragments with the appropriate cone voltage. Solid Phase Extraction (SPE) was carried out for the pretreatment of urine specimens, and various conditions were studied to recover vancomycin and teicoplanin spiked concentrations.

Results: The developed analytical protocol showed a good resolution between vancomycin and teicoplanin with retention times of 6.966 and 7.976 minutes, respectively. For the validation, the method indicated linearity with $R^{2} \geq 0.9990$ while the intra-day and inter-day precisions were estimated with values of maximum coefficient of variation (\%CV) equal to $6.592 \%$, which are below the $10 \%$. Limits of detection (LOD) and quantification (LOQ) were estimated between $0.0252-0.785 \mathrm{mg} / \mathrm{L}$ and $0.0764-2.4197 \mathrm{mg} / \mathrm{L}$, respectively. Recovery at low and high concentrations of vancomycin and teicoplanin was examined in water samples, ranging from 64 to $121 \%$, showing relatively good recoveries.

Conclusions: Successful development of analytical protocol using HPLC-MS for the simultaneous determination of vancomycin and teicoplanin in urine showed good linearity, repeatability, and accuracy, such as low values of LOD and LOQ. However, the developed SPE protocol requires further study to achieve better recoveries in the range of $80-100 \%$.

\section{Quantitative analysis and comparison of pesticide residue in green tea}

I. Taal, L. Parts, K. Eha

Tallinn Health Care College, Tallinn, Estonia

Introduction: Green tea is one of the most consumed drinks in the world. It is taken often daily, as it has no specific pharmacological effects. Due to the high intake of green tea, it is essential to determine the safety of the tea. This research aims to study green tea, its properties, the impact of pesticides on human health, and analyse the content of pesticide residues in green tea sold in retail and their compliance with the limits set in the European Union (EU).

Materials and methods: The sample consisted of five green teas without additives. Samples were prepared according to the QuEChERS method (EN 15662) and analysed with gas chromatography-mass spectrometry. The results were compared with the limits established by the EU.

Results: Of the five samples, one did not contain any pesticides at all, four were found to contain pesticide residues, and two showed traces of pesticides. Two samples contained pesticides above the maximum level authorised in the EU, and one sample contained four pesticides and one pesticide trace. Four of the six pesticides identified in the study are banned in the EU: hexachlorobenzene, bifenthrin, fenpropathrin, and permethrin.

Conclusions: Green teas sold in Estonia contain traces of pesticides. None of the sampled teas carried pesticide residues above the EU standards, although some pesticides found are prohibited in the EU. Further research is needed to determine the rate of pesticide residue transmission into beverages during brewing. 